\title{
The use of paper dictionary on L2 vocabulary learning and retention \\ 1Zuraina Ali
}

Email : 1zuraina@ump.edu.my

Centre for Modern Languages, Universiti Malaysia Pahang, 26600 Pekan, Pahang, Malaysia

ARTICLE INFO

Article history

Received: 10 September 2021

Revised: 15 September 2021

Accepted: 30 September 2021

Keywords

Vocabulary

Learning

Retention

Paper dictionary

Dictionary strategy

\section{ABSTRACT}

Vocabulary learning and retention are two components that are essential in assessing students' abilities to understand the meaning of words. The study examines students' attitudes toward learning vocabulary and their learning feedback of using a paper dictionary. It also investigates the factors that students favor and dislike when using the resources for vocabulary retention. Explanatory Sequential Research Design is employed to collect the data in the current study. Both, questionnaires and semi-structured interviews are utilized as the instruments in the current study. The study found that students had positive learning attitudes using a paper dictionary in learning vocabulary. There was also various learning feedback that was obtained concerning the use of the resource for the learning of vocabulary. In terms of vocabulary retention, students provided different viewpoints in the use paper dictionary to assist them in memorizing the definition of a target word. Finally, the study found a few factors that restricted them to use the resources to retain the vocabulary learned. The study implies that the use of a paper dictionary is still significant as it helped students to enhance their understanding of a particular vocabulary.

This is an open access article under the CC-BY-SA license.

\section{INTRODUCTION}

Using a dictionary to know the meaning of a particular word is essential for students especially for non-native speakers. The resource enables language learners to know how words can be used and at the same time retain the words they have learned (Chen, 2017). In his study, an electronic dictionary was used to investigates the relationship between dictionary use behavior and the production and retention of collocations. Surprisingly, there was no significant behavior found relating to these variables. There was no difference in students' search for base words nor other words involved in the collocation. Yet, with students' limited knowledge of the target collocation, the researcher found that electronic dictionaries helped students to know the use of collocation as well as retain it. Similarly, Knežević et al. (2021) conducted a study on millennials; Serbian English as A Foreign Language (EFL) learners' behavior in their habits of using the dictionary. It was found that the majority of them had printed bilingual dictionaries or bilingual paper edition dictionaries. But the resources were only kept on the shelves of their houses. They almost never used the dictionary when learning English. Yet, they used online bilingual 
dictionaries almost at all times to look up for the meaning of unknown words. Sadly, however, they did not use entry information in the resources that much despite being technology savvy.

Studies on the use of dictionaries were also conducted to know its benefit in translation. Fredholm (2019) in his study employed a printed dictionary to compare its effectiveness in translation with that of Google translation for Spanish vocabulary development. Interestingly, although it was found that the latter enabled learners in his study to attain vocabulary size, its use, however, might not help them in obtaining a deeper understanding of a target word (vocabulary depth). The study concluded that there was a need to have varying explicit instructions of translation tools and strategies in learning Spanish vocabulary. The printed dictionary seems to be less popular nowadays compared to an online dictionary and online translator. Alhaisoni (2016) found that English as a Foreign Language (EFL) teachers that were employed as samples in his study used online dictionaries and Google translator besides bilingual printed dictionary in their teaching. In his study, printed bilingual dictionaries obtained the lowest mean ( $(\mathrm{x})$ compared to the use of other resources that were Google translator and mobile dictionary. The interview that was conducted in his study reported that they used a mobile dictionary to check unknown words that were installed in the smartphones. And sometimes used Google translator to speed up the process of finding unknown words. The dictionary helps professionals; copywriters, novelists, translators, and other professional writers, to understand the use of phrases (Hill et al., 2016). The use of computational semantics developed by the researchers helped professionals in using appropriate phrases using two types of dictionaries reverse dictionary/ concept finder dictionary and general-knowledge crossword question answerer. The neural language embedding models in their study proved that they could map dictionary definitions (phrases) to representations of the words defined by those definitions.

The use of dictionaries was also employed in research related to vocabulary learning (Govindasamy et al., 2019; Hakim et al., 2020). Dictionary can be used to enrich learners' vocabulary size. Participants in Hakim's et al. (2020) study were placed in the control group employing a printed dictionary while those who used e-dictionary were assigned to an experimental group. Findings from the study revealed that participants using e-dictionary scored better at vocabulary tests compared to those who used printed dictionaries. It was concluded that e-dictionary could be powerful tool for vocabulary learning. Another study on learning vocabulary between printed dictionaries with mobile-assisted vocabulary learning showed that the latter was more effective than the former. Govindasamy et al. (2019) found that images and pronunciation of a word (audio or video) when students browsed its meaning on the Internet, helped them better to enrich their vocabulary knowledge. 
Meanwhile, there were studies investigated on the use of dictionaries for vocabulary retention (Apriliani, 2018; Putri, 2019). A study found that Google dictionary was not effective in helping students to retain the meaning of an unknown word (Putri, 2019). Although participants who were assigned to use Google dictionary completed their reading faster compared to those who used printed dictionary, the former group, however, were not able to retain the words learned. Those who used printed dictionaries spent more time looking up for meaning and understanding the target words, were found to retain words they learned longer compared to their counterparts. Similarly, an electronic dictionary, Line Dictionary, was not able to make students retain the target vocabularies (Apriliani, 2018). Although they often looked up the meaning for unknown words several times in Line Dictionary, they, however, were not able to recall their meaning when they were assigned a reading task. However, a smaller number of students could understand the target words referring to the contexts of their uses. The researcher concluded that the tool only enabled participants in her study to retain words for short-term retention. Another investigation on vocabulary retention using the dictionary, in particular edictionary, was conducted by Fadila (2019). She found that non-proficient students were not able to retain the words they looked up upon understanding the reading text that was assigned to them. They were reported to consult the e-dictionary more often than trying to understand the text.

Having to elaborate the background of the study, a systematic understanding of how printed dictionary contributes to the learning and retaining of the target word is still lacking. Majority of the research in the previous discussions employed e-dictionary to gauge vocabulary retention among learners. Albeit, it assisted learners to learn vocabulary, what is less clear is the nature of the dictionary itself that is not comprehensive as the printed ones. The use of the latter enables learners to explore the meaning of words and fuel them with curiosity (Biba, 2019). Moreover, there is still uncertainty, however, as to the learners' attitudes in using a printed dictionary. The idea is worth investigating in the current research as it helps the researcher to identify the learners' satisfaction or commitment using the resource (Bret, 2009).

Therefore, four (4) research questions are formulated in the use of paper dictionary among second language learners for vocabulary learning and retention. The first two research questions examine the general idea of how paper dictionaries are used among students. The remaining research questions, however, specifically investigate the use of paper dictionary in retaining vocabulary. The research questions of the study are:

1. What are the students' attitudes of learning vocabulary using paper dictionary?

2. What are the students' learning feedback using paper dictionary?

3. What are the factors that students favour in the use of paper dictionary for vocabulary retention? 
4. What are the factors that restrict students from retaining vocabulary using paper dictionary?

\section{METHOD}

The study employed a mixed-method research design specifically explanatory sequential research design. Creswell (2014) states that in using the design, researchers collect and analyse quantitative data then it is followed by the collection and analysis of qualitative data. After both types of data are collected and analysed, the interpretation process takes place. Figure 1 shows the Explanatory Sequential Research Design uses in the study.

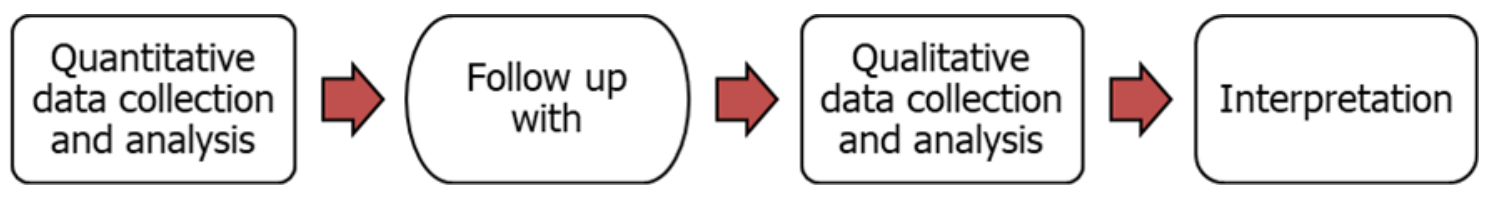

Figure 1. Explanatory Sequential Research Design

Source: Creswell (2014)

The samples in the study are majoring in engineering and studying at one of the universities in the East Coast of Malaysia. Prior to conducting the survey, vocabulary tests were administered to the students after they were provided and taught to use dictionary; 8th edition of Oxford Advanved Learners' Dictionary (OALD). Among the dictionary strategy learned were looking up words in the entries/sub-entries; using addendum, learning functions and symbols, to name a few. Then, they were required to complete a questionnaire. After that, selected students were called to participate in a semi-structured interview. However, the current report of this paper focuses on the data obtain from the questionnaire and semi-structured interview only.

For samples involved in the survey, 37 engineering students were chosen to complete the items in the research instrument. In particular, purposive sampling was used in selecting them in that they were assumed to represent the population of students learning and retaining vocabulary. In addition, four (4) students were involved in the semi-structured interview. Two (2) of them were represented students who scored high scores (competent learners) and another two (2) were low scorers (basic learners). Bahasa Melayu was permitted to be used in giving their feedback. The four (4) students for the interview were selected on voluntarily basis.

In terms of checking the reliability of the instruments, the alpha coefficient scores for the questionnaire is 0.90 and therefore, reliable to be used in the study. Its validity was assessed by two (2) lecturers that hold a degree in teaching English and Linguistics. In addition, content 
validity was conducted to assess the items in the semi-structured interviews. A lecturer with Linguistics major was appointed to assess its validity.

Regarding data analysis, descriptive statistics was employed to analyse the quantitative data. Specifically, mean ( $(\mathrm{x})$ and standard deviation $(\sigma)$ were employed to analyse Research Questions 1 and 2. Content analysis, on the other hand, was used to analyse the qualitative data to answer Research Questions 3 and 4. Thematic coding was employed for the recording of texts in that common themes are linked to one another to formulate categories (Joffe, 2012).

\section{FINDINGS AND DISCUSSION}

This section explains the results of the study in relation to the research questions that are formulated at the beginning of the research. Also, discussion is provided to elaborate the findings that are supported by relevant previous studies. In presenting this part, results of the study are presented first and later it is followed by discussion.

\section{Students' attitude of learning vocabulary using paper dictionary}

Table 2 demonstrates students' attitude of learning vocabulary using paper dictionary. It showed that the highest mean $(M=3.97, S D=0.60)$ was for Item 7 in that they believed that it was an opportunity for them to learn new words using paper dictionary. Another high mean is for Item 1 that indicated that they could enrich their vocabulary when instructed to use the material to know meaning of words. In addition, they viewed moderately the use of paper dictionary in helping them to increase their skills in learning vocabulary $(M=3.78, S D=0.54)$, letting them know the appropriate ways to use dictionary to find target words $(\mathrm{M}=3.76, \mathrm{SD}=$ $0.64)$, using the paper dictionary better in the future $(\mathrm{M}=3.70, \mathrm{SD}=0.66)$, and realising that the method of using paper dictionary is suitable for their vocabulary learning approaches $(M=3.70$, $\mathrm{SD}=0.57)$. Nevertheless, they did not agree that the paper dictionary could help them in memorising the meaning of words as showed in item 10 having the lowest mean $(M=3.19$, $\mathrm{SD}=0.91)$.

Table.1 SCORES ON STUDENTS' ATTITUDE IN LEARNING VOCABULARY USING PAPER DICTIONARY

\begin{tabular}{llrr}
\hline & & \multicolumn{2}{c}{$\begin{array}{c}\text { Dictionary } \\
\text { Strategy }\end{array}$} \\
\cline { 3 - 4 } Items & \multicolumn{2}{c}{ Mean } & SD \\
\hline $1 . \quad \begin{array}{l}\text { I could enrich my } \\
\text { vocabulary } \\
\text { using the method. }\end{array}$ & 3.92 & 0.43 \\
& & &
\end{tabular}




\begin{tabular}{|c|c|c|c|}
\hline 2. & $\begin{array}{l}\text { I could increase my skills } \\
\text { in learning vocabulary } \\
\text { using the method. }\end{array}$ & 3.78 & 0.54 \\
\hline 3. & $\begin{array}{l}\text { I could improve my } \\
\text { vocabulary using the } \\
\text { method. }\end{array}$ & 3.84 & 0.50 \\
\hline 4. & $\begin{array}{l}\text { I could follow or keep up } \\
\text { with the learning of } \\
\text { vocabulary using the } \\
\text { method. }\end{array}$ & 3.76 & 0.64 \\
\hline 5. & $\begin{array}{l}\text { I could make the best use } \\
\text { of the method in learning } \\
\text { vocabulary. }\end{array}$ & 3.70 & 0.66 \\
\hline 6. & $\begin{array}{l}\text { I could increase my } \\
\text { knowledge about the } \\
\text { words I learned, using the } \\
\text { method. }\end{array}$ & 3.81 & 0.74 \\
\hline 7. & $\begin{array}{l}\text { I had a good opportunity } \\
\text { to learn vocabulary using } \\
\text { the method. }\end{array}$ & 3.97 & 0.60 \\
\hline 8. & $\begin{array}{l}\text { I was motivated to use the } \\
\text { method in learning } \\
\text { vocabulary after I was } \\
\text { introduced to it. }\end{array}$ & 3.68 & 0.82 \\
\hline 9. & $\begin{array}{l}\text { I noticed that my } \\
\text { understanding of } \\
\text { vocabulary learning had } \\
\text { changed after being } \\
\text { exposed to the method. }\end{array}$ & 3.43 & 0.77 \\
\hline 10. & $\begin{array}{l}\text { I could memorise the } \\
\text { meaning of words I } \\
\text { learned easily using the } \\
\text { method. }\end{array}$ & 3.19 & 0.91 \\
\hline 11. & $\begin{array}{l}\text { I could recall the meaning } \\
\text { of words I learned easily } \\
\text { using the method. }\end{array}$ & 3.30 & 0.85 \\
\hline 12. & $\begin{array}{lr}\text { I enjoyed } & \text { learning } \\
\text { vocabulary } & \text { using } \\
\text { the method. } & \end{array}$ & 3.65 & 0.68 \\
\hline 13. & $\begin{array}{l}\text { I found that it is } \\
\text { interesting to use the } \\
\text { method in learning } \\
\text { vocabulary. }\end{array}$ & 3.49 & 0.870 \\
\hline 14. & $\begin{array}{l}\text { I found that the method } \\
\text { was suitable for my kind of } \\
\text { vocabulary learning. }\end{array}$ & 3.70 & 0.57 \\
\hline
\end{tabular}

The finding on an opportunity for them to learn new words using paper dictionary is consistent with that of Filer (2016). His study showed that learning new words using paper dictionary enabled language learners to know the meaning of a particular term due its simplified language. This outcome, however, is contrary to that of Hakim et al. (2018) who found that paper dictionaries are less powerful to assist learners in learning vocabulary. Students who were taught 
using electronic dictionaries learned better compared their counterparts. Such was due to electronic dictionaries speed the looking up of new words compared to the printed dictionaries. The fact that the students in the current study stated that they were not able to memorise the meaning of words learned using paper dictionary was a disappointing discovery. Yet, looking up definition in the resources could guarantee their vocabularies to be sky rocketed (Kevin, 2020). Also, it helps learners to accelerate their proficiency in the language - especially in learning foreign languages (Peters, 2020).

\section{Students' learning feedback using paper dictionary}

Students in the current study were required to provide learning feedback after they know how to use paper dictionary to retain target vocabulary. Findings for the current research question was obtained from the open-ended items in the questionnaire. As this section was optional, they may or may not provide feedback from their learning on the use of paper dictionary. Table 2 showed that Item 2 obtained the highest frequency in that 22 of them described that the paper dictionary enabled them to know the various definitions of a particular target vocabulary. They also admitted that they were able to identify the use of the target vocabulary in sentences $(n=14)$. The learning of grammar $(n=13)$ was another feedback that was obtained from the open-ended items. The least learning using paper dictionary in relation to vocabulary attainment was for the learning of symbols $(n=9)$.

Table.2 LEARNING FEEDBACK OF USING PAPER DICTIONARY IN LEARNING VOCABULARY

\begin{tabular}{clc}
\hline No. & \multicolumn{1}{c}{ Item } & Frequency \\
\hline 1. & Able to be aware of grammatical information & 13 \\
2. & Able to know various definitions of a single word & 22 \\
3. & Learning symbols & 9 \\
4. & Able to know how target words are used by looking at the example of & 14 \\
& sentences & \\
\hline
\end{tabular}

It was true that students might know various definitions of a vocabulary as found in the current study $(n=22)$. Yet, if they were reluctant to find other words that were associated with the word they were looking for, their understanding of the words might be out of context (Bastomi, 2016). This is because each definition of a particular word provides different meaning. Therefore, when students look up for a definition, they would be finding the word based on the context of how it is used. This shows that consulting dictionaries is important to know various definitions of a word. 


\section{Factors that students favour in the use of paper dictionary for vocabulary retention}

Answers for this research question were derived from the interview that was conducted among students who obtained high scores in the vocabulary tests. Two (2) main themes were produced in relation to the research question.

\section{Various Definitions Guide Understanding}

Definitions seem to give a great deal of benefit to competent learners in the Dictionary Strategy group to learn and understand the meaning of a target word and thereby assist them in retaining it. In fact, looking at definitions made a better use of the dictionary. Kim put it thus:

Looking at the definition is the first thing I do when I refer to dictionary to find meaning of a word. I think it is important because you need to know meaning of word [that you want to find]. If not, you cannot know how to use the word... I think, to make the use of dictionary effective to us, we need to highlight the definitions. Then we can memorise much better. Just like when we're studying for important points in the subjects we take.

In using the dictionary, shorter definitions enabled competent learners to retain the meaning of the words better than the longer ones. Hani gave one example of her experience regarding this point:

If the definition is short maybe I can understand and of course remember the word. For instance, the word 'inanity' or 'inanities' I learned in the lesson, I still remember that it means 'silly'. The definition is short when I refer to the dictionary. So, I can remember it easily compared to 'tapestries'...that one is longer than 'inanity'.

\section{Feasibility of Knowing Examples of Sentences}

The dictionary provides several meanings for a word. Competent learners believed that studying the examples of sentences illustrating the use of the target words enabled them to retain the words learned. Kim said: "I think we need to know how to use the words, it's much better. Usually aaa...we just know the meaning [of a word], but we don't know how to use the word. So, we cannot put [write] the words in sentences. But when you use dictionary, you can refer to how the words are used. So, from dictionary we can find the example of sentences". Hani too, considered the procedure of looking at examples of sentences to be important in the cause of retaining words, as she gave a scale from eight to nine out of ten points during the interview. She remarked: 
I just look at all the entries [containing definitions] stated for the target words. I usually read sentences first... I try to understand the sentence first... after I read all the entries, then only I determine the one that is suitable for the [target] word. I give a scale of eight to nine [out of ten] because I know when we use dictionary, we may not only find the meaning of the word we want, but we also know examples [of sentences] for the word.

Meanwhile, competent learners in Dictionary Strategy favoured using the resource as they were able to know various definitions of a target word. This helps them understand the meaning of the vocabulary before retaining it. Several definitions are provided in the OALD to help the students obtain the meanings of a word. For instance, three definitions were provided for 'accent', four for 'poach', five for 'stitches', etc. Yet, the usefulness of various definitions in the monolingual dictionary was inconsistent with Chan's (2005) finding. Students in Chan's (2005) study were not able to retain the meaning of the target words when there were too many definitions for the words. They were not able to figure out the appropriate multi-sense meanings of particular words or the correct usage of a target word. One student in Chan's (2005) study chose the first but inappropriate definition for the meaning of 'anxious' instead of the last but appropriate meaning, although she went through all the examples of sentences provided for the word. Chow (2001) argues that such is the result when students are unable to decide on the meaning of a word in context.

Besides that, competent learners preferred looking up words in the dictionary because it helped them to identify the uses of the words by reading the examples of sentences. Moreover, target words utilised in combination with other individual known words can ensure their placement in the long-term memory (Chen, 2008). Such findings contradict Chan's (2005) finding in that respondents in her study found that understanding the examples of sentences was a disappointment. In fact, they viewed that the examples provided in the dictionary were not useful as they were not able to understand the explanations given. Some respondents thought that the numerous examples given for a particular entry puzzled them. Even after checking a dictionary, they still could not figure out the appropriate meanings of a multi-sense word or the correct usage of a target item.

\section{Factors that restrict students from retaining vocabulary using paper dictionary}

Two (2) themes were formulated to identify the reasons that restrict students from retaining vocabulary using paper dictionary. These are 'Various Entries Impeded Usefulness' and 'Flipping Pages of Dictionary Is a Lazy Task' were the two (2) themes that were identified in relation to the hindrances of using Dictionary Strategy in retaining vocabulary. 


\section{Various Entries Impeded Understanding of Meaning of Target Words}

As there are various definitions that are printed for a single word, basic learners viewed this as a problem, as the definitions distracted their attention. Failing to identify the definition resulted in their inability to retain the meaning of the words learned. Salina, for instance, felt that only the first definition was important to her. Other definitions, she perceived, were not related to the target word. She noted:

All these while I look at only one entry. I was not bothered with the rest of the definition unless for the first one. I noticed in the lesson that there are various definitions for a single word- but it was long...so, I didn't read all of them. After all, I seldom use dictionary. I only take the meaning [that is located] at the front only. I was not bothered with other meanings [even] if I read.

Ahmad also felt that the various definitions hindered him in looking-up the meaning of the target word: "...there were just too many definitions for each of the words that I had to find" (terdapat terlalu banyak makna untuk satu-satu perkatan yang nak [hendak] dicari). He, therefore, contemplated that the rest of the definitions were not important. "I thought they were not important. So, I looked at the ones which I think were important" (Lagi pun saya tak [tidak] [meng]gunakannya. Saya ingat benda [makna perkataan] [i]tu tak penting. Jadi, saya tengok makna yang saya rasa penting sahaja).

\section{Flipping Pages of Dictionary Is a Lazy Task}

Laziness in flipping pages of the dictionary obviously made the use of the dictionary less effective. Ahmad demonstrated that he sang the $\mathrm{ABC}$ song softly while he flipped the pages of the OALD to find meanings of the target words. He was sluggish because the process of flipping was slow. He imparted such experience in the excerpt below:

Ok, first if I want to know the word 'eye'; for instance, right? Firstly, I need to find the letter 'e' then ' $y$ ', later 'e'. That's why I feel lazy to find meaning of a word because it's slow [a slow process]...so, I am so lazy...It also takes time. Often, I cannot remember the sequence of the alphabet... a-b-c-d-e-f-g... [singing $\mathrm{ABC}$ song] sometimes I need to do that. Dictionary book like this takes time to use. So, it makes me slow in flipping the pages [of the dictionary]... I need to take time [to find the word].

In fact, searching for the words themselves caused a problem to the basic learners. In the excerpt below Salina demonstrated that she requested the teacher to repeat spelling the word 'hedhehog' when she was told to flip the pages of dictionary in finding the entries for the word. 
Teacher: $\quad$ Okay... Let me give you an example. Can you find the meaning of hedhehogs in this dictionary?

Student: $\quad \mathrm{H}-\mathrm{e}-\mathrm{d}-\mathrm{g}-\mathrm{e}-$ ?

Teacher: 'Hedhehogs'... h-e-d-g-e-h-o-g ... plural is 'hedhehogs'

In the use of the dictionary, the basic learners claimed that the various entries in the resource impeded their understanding of the meaning of the target words. Waring (2000) states that finding of the target words in the English-English dictionary requires a few processes which are not favoured by its users. In fact, it is a challenging assignment to L2 learners. Also, when they found the target word, again, they would be spending time on trying to understand its various meanings. Since they need to read every single definition to identify the most suitable one, they tend to forget it when requested to recall it. The interference theory explains that the inability to remember some materials is due to the interference that is caused by other materials in the memory (Bower, Thompson-Schill \& Tulving, 1994). Hence, in reading the definitions, it leads to competition in remembering one definition from another (Symthe, Jutras, Bramwell \& Gardner, 1973). Due to this, they may tend to forget the definitions that need to be recalled in the test.

\section{CONCLUSION}

This paper has discussed four main issues concerning students' attitude of learning vocabulary using paper dictionary, their learning feedback using paper dictionary, factors that they favour in the use of the platform for vocabulary retention and finally factors that restrict them to retain vocabulary using the resource. The study has identified that, in general, they had positive attitudes using the paper dictionary. It has also shown that students realised that there were various ways of learning vocabulary when they used paper dictionary. There were different views that made them enjoyed and disliked using the resources in retaining words learned. The findings of this study suggest that students need to be taught the use of dictionary. In the current study, participants had the chance to know effective strategies of using the resources. It could be said that the study was the first attempt for them to learn the use of the resources systematically. This study has gone some way towards enhancing our understanding of the significant use of the paper dictionary. Nevertheless, the study should be repeated using a larger sample size. Also, there is a need to lengthen the duration for the training to use the dictionary as the participants in the current study had one-off day session only.

\section{ACKNOWLEDGEMENTS}

The author would like to thank the participants involved in the study. Also, thanks go to the anonymous referees for their useful suggestions in improving this paper. 


\section{REFERENCES}

Alhaisoni, E. (2016). EFL Teachers' and Students' Perceptions of Dictionary Use and Preferences. Article in International Journal of Linguistics, 8(6). https://doi.org/10.5296/ijl.v8i6.10267

Apriliani, A. (2018). The students' use of line dictionary application in reading activity on the second grade at SMAN 1 Porong academic year 2017-2018. UIN Sunan Ampel Surabaya.

Arif Rahman Hakim, Abidin, M. J. Z., \& Bahari, A. I. (2018). Dictionary Use to Increase Students' Vocabulary Mastery: Electronic Dictionary or Printed One? 150-159. https://doi.org/10.5220/0008215001500159

Bastomi, R. (2016). Dictionary Usage In English Language Learning. 9(1), 186.

Biba, J. (2019). 5 Benefits of a Print Dictionary | Scholastic | Parents. https://www.scholastic.com/parents/books-and-reading/raise-a-readerblog/childrens-dictionary.html

Bret, L. S. (2009). The Importance of Understanding Personalities and Attitudes. http://www.bretlsimmons.com/2009-07/the-importance-of-understandingpersonalities-and-attitudes/

Chen, Y. (2017). Dictionary use for collocation production and retention: A CALL-based study. International Journal of Lexicography, 30(2), 225-251.

Creswell, J. W. (2014). The Selection of a Research Approach. In Research Design:Qualitative,Quantitative, and Mix Methods Approaches (4th ed., pp. 3-23). SAGE. https://doi.org/45593:01

Fadila, S. F. (2019). The Effect of Electronic Dictionary and Reading Interest on Students' Vocabulary Knowledge (A Quasi-experimental Study at the Eighth Grade of SMP Al Falah, Mampang Prapatan). Jakarta: Fakultas Ilmu Tarbiyah Dan Keguruan UIN Syarif Hidayatullah.

Filer, B. (2016). Paper or Electronic Dictionaries: A Comparison. In \& H. B. Clements, A. Krause (Ed.), Transformation in Language Education. Tokyo: JALT.

Fredholm, K. (2019). Effects of Google translate on lexical diversity: vocabulary development among learners of Spanish as a foreign language. Revista Nebrija, 13(26), 98-117.

Govindasamy, P., Yunus, M. M., \& Hashim, H. (2019). Mobile assisted vocabulary learning: Examining the effects on students' vocabulary enhancement. Universal Journal of Educational Research, 7(12A), 85-92.

Hakim, M. A. R., Abidin, M. J. Z., \& Bahari, A. (2020). Dictionary Use to Increase Students' Vocabulary Mastery: Electronic Dictionary or Printed One. Proceedings of the 1st Bandung English Language Teaching International Conference, 1, 150-159.

Hill, F., Cho, K., Korhonen, A., \& Bengio, Y. (2016). Learning to Understand Phrases by Embedding the Dictionary. Transactions of the Association for Computational Linguistics, 4, 17-30. https://doi.org/10.1162/tacl_a_00080/1567364/tacl_a_00080.pdf

Joffe, H. (2012). Thematic analysis. Qualitative Research Methods in Mental Health and Psychotherapy: A Guide for Students and Practitioners, 1, 210-223.

Kevin, A. (2020). 6 Tips for Learning New Words | British Council Foundation Indonesia. https://www.britishcouncilfoundation.id/en/english/articles/new-words

Knežević, L., Halupka-Rešetar, S., Miškeljin, I., \& Milić, M. (2021). Millennials as dictionary users: A study of dictionary use habits of Serbian EFL students. SAGE Open, 11(2), 
21582440211008424.

Peters, B. (2020). 7 Reasons You Should Look Up Words You Don't Know. https://creatorvilla.com/2020/04/01/7-reasons-you-should-look-up-words-you-dontknow/

Putri, D. F. (2019). The Practicality of Google Dictionary for Vocabulary Retention among EFL Undergraduate Students. UIN Ar-Raniry Banda Aceh.

\section{BIOGRAPHY OF AUTHOR}

Associate Prof. Dr. Zuraina Ali is a Senior English lecturer at the Centre for Modern Languages \& Human Sciences (CMLHS) in Universiti Malaysia Pahang (UMP). Her research interests include vocabulary, technology-related issues on language teaching, the use of new webbased learning environments to support learning and vocabulary learning among language learners. 